九州大学学術情報リポジトリ

Kyushu University Institutional Repository

\title{
Delayed Light Emission as a Means of Automatic Color Sorting of Persimmon Fruits (Part 2): DLE Characteristics as a Means of Color Sorting
}

Chuma, Yutaka

Laboratory of Agricultural Process Engineering, Faculty of Agriculture, Kyushu University

Nakaji, Ke i

University Farm, Faculty of Agriculture, Kyushu University

McClure, W. F.

Department of Biological and Agricultural Engineering, North Carolina State University

https://doi.org/10.5109/23754

出版情報: 九州大学大学院農学研究院紀要. 27 (1/2)，pp.13-20，1982-10. Kyushu University バージョン：

権利関係 : 
J. Fac. Agr., Kyushu Univ., 27 (1.2), 13-20 (1982)

\title{
Delayed Light Emission as a Means of Automatic Color Sorting of Persimmon Fruits (Part 2)
}

\author{
DLE Characteristics as a Means of Color Sorting
}

\author{
Yutaka Chuma \\ Laboratory of Agricultural Process Engineering, Faculty of \\ Agriculture, Kyushu University 46-05, Fukuoka 812 \\ Kei Nakaji \\ University Farm, Faculty of Agriculture, Kyushu \\ University, Kasuya-Cho, Fukuoka, 811-23

\section{W. F. McClure} \\ Department of Biological and Agricultural Engineering, \\ North Carolina State University, Raleigh., N.C., U.S.A.
}

(Received March 30, 1982)

\begin{abstract}
DLE intensity of persimmons was investigated to evaluate the peel color and maturity of the fruits. Color sorting test by DLE was conducted based on the coloring index used in the packinghouse line. The DLE intensity decreased remarkably with the increase in coloring maturity. Bruising of the fruit caused a shortterm increase in DLE intensity with a subsequent drop after 24 hours of storage. Persimmon fruits classified visually into four groups according to the hue of peel color were experimentally sorted with high accuracy by means of DLE except for the color group of "Yu". Thus the DLE method was considered to be useful for mechanical sorting of persimmon fruits.
\end{abstract}

\section{INTRODUCTION}

Some basic characteristics of persimmons were investigated in a previous report (Chuma et al., 1982) where it was shown that the chlorophyll content of persimmons could be determined by DLE measurements. Since there is a correlation between chlorophyll and maturity, the maturity of persimmons could be determined by measuring DLE intensity. The research reported here makes use of the results from the above study to investigate the practical application of DLE for persimmon sorting.

\section{MATERIALS AND METHODS}

The materials and methods employed in this research were similar to those used in the previous report. Persimmon fruits (Diospyroskaki Linn. f. var. Fuyu) were harvested from two adjacent persimmon trees at intervals of 7 days from September 14 to November 16, 1976. Ten fruits were taken from tree no. 1 and 5 fruits from tree no. 2 at each harvest interval. The fruits 
were taken evenly from throughout the tree-production zone. The conditions for DLE production were a dark period of $10 \mathrm{~min}$, an excitation illuminance of $1,750 \mathrm{~lx}$, and an excitation time of $2 \mathrm{~min}$.

Fruit color was determined by thk Munsell hue, value, and chroma based on the color index table of the Japan Industrial Standards JIS Z 8721 and JIS $\mathrm{Z}$ 8723. Two observers were used to make the color determinations.

The effect of bruising on DLE intensity was determined in the following manner. First, the DLE of normal fruit was measured under the standard conditions (see Figs. 1 and 3). Then each fruit was dropped $50 \mathrm{~cm}$ onto a smooth concrete floor. DLE was measured by the standard conditions after $10 \mathrm{~min}$ dark period. The fruit was then stored 24 hours in the dark; the DLE of the same bruised section was measured again.

\section{RESULTS AND DISCUSSION}

\section{Application of DLE for sorting persimmons}

The intensity of DLE decreases dramatically with harvest date (see Fig. 1). Fruit from tree no. 1 began to change color during the first 10 days of October, but from the standpoint of taste the optimum harvest time was the last 10 days of November.

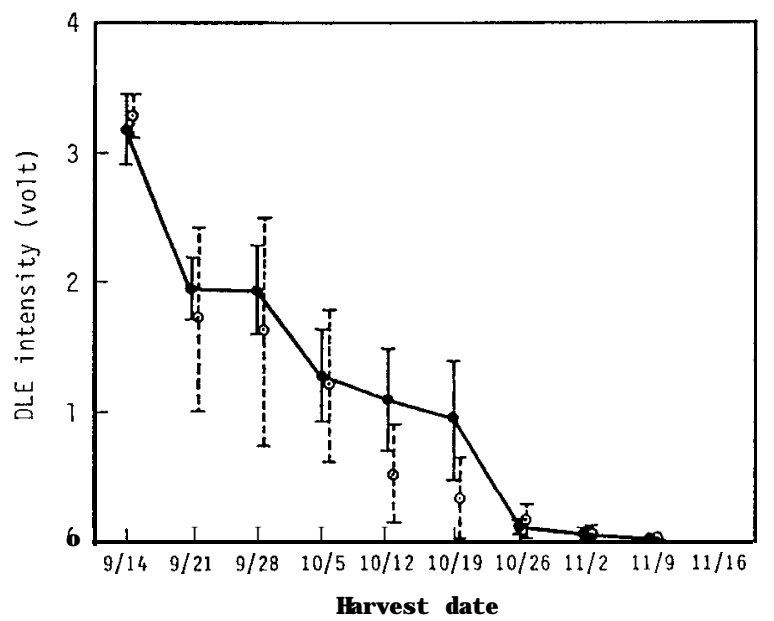

Fi g. 1. DLE intensity as a function of harvest date for persimmon. Conditions for determination of DLE: $10 \mathrm{~min}$ dark period, $2 \mathrm{sec}$ excitation period, $1,7501 \mathrm{x}$ illuminance, $0.7 \mathrm{sec}$ decay period, and $19.9-24.5{ }^{\circ} \mathrm{C}$ fruit temperature. : tree no. 1; $\odot$ : tree no. 2. Vertical lines: 95 percent confidence interval.

Degradation of DLE for tree no. 2 followed a similar pattern to that of tree no. 1, but the decay was somewhat faster during the period of time from 10/12 to 10/19. The fruits on tree no. 2 reached optimum harvest time earlier 


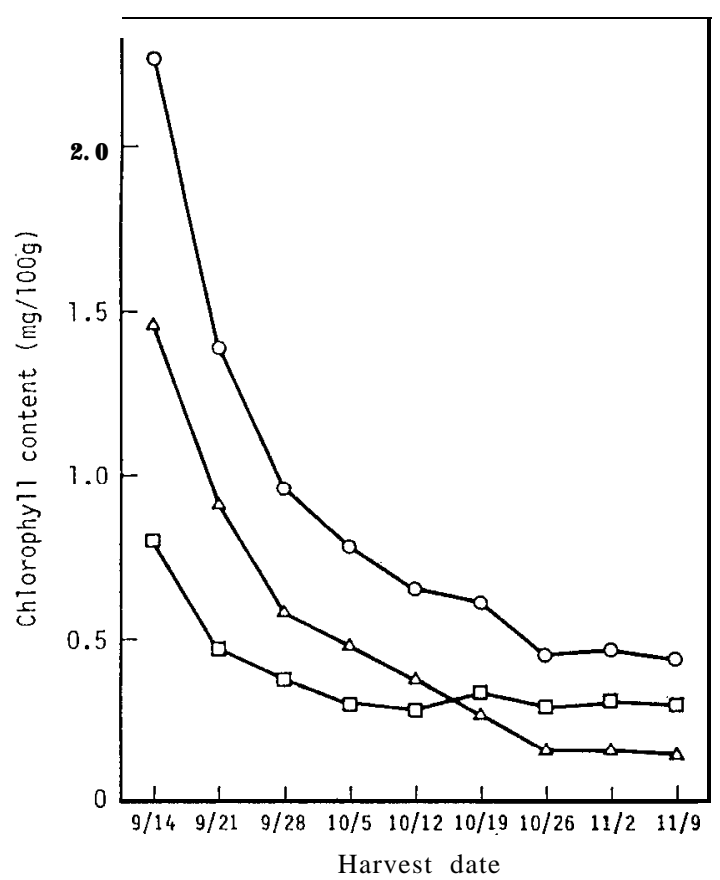

Fig. 2. Chlorophyll content as a function of harvest date for persimmon. $\mathrm{O}$ : chlorophyll $(\mathrm{a}+\mathrm{b}) ; \wedge$ : chlorophyll a; $\square$ : chlorophyll b.

than the fruit on tree no. 1.

Fig. 2 confirms the fact that DLE is a function of chlorophyll content of the persimmons. Each point on the 'curves are the mean chlorophyll content of the 10 fruits harvested from tree no. 1 on the dates given. It should be noted that the curves for chlorophyll $\mathrm{a}$ and $(\mathrm{a}+\mathrm{b})$ have a similar shape to the curves in Fig. 1.

\section{Relationships between peel color and DLE intensity}

According to Grassman's Law, three independent elements or variables are needed to properly evaluate the color of any product. The horizontal axis in Fig. 3 shows the Munsell hue which varies from greenish-yellow on the left to red on the right. GY, Y, YR, and R are greenish-yellow, yellow, yellowish-red, and red hue color respectively. DLE decreases almost linearly from $2.5 \mathrm{GY}$ to $5 \mathrm{YR}$. This indicates that DLE is a good indicator of peel color.

As can be seen from Fig. 4 there was no apparent relationship between the Munsell value and DLE intensity. The value of the samples ranged from 4 (over-ripe) to 8 for ripe fruits. The arrows in Fig. 4 indicate how the value changed with harvest date; first increasing and then decreasing as time passed. 


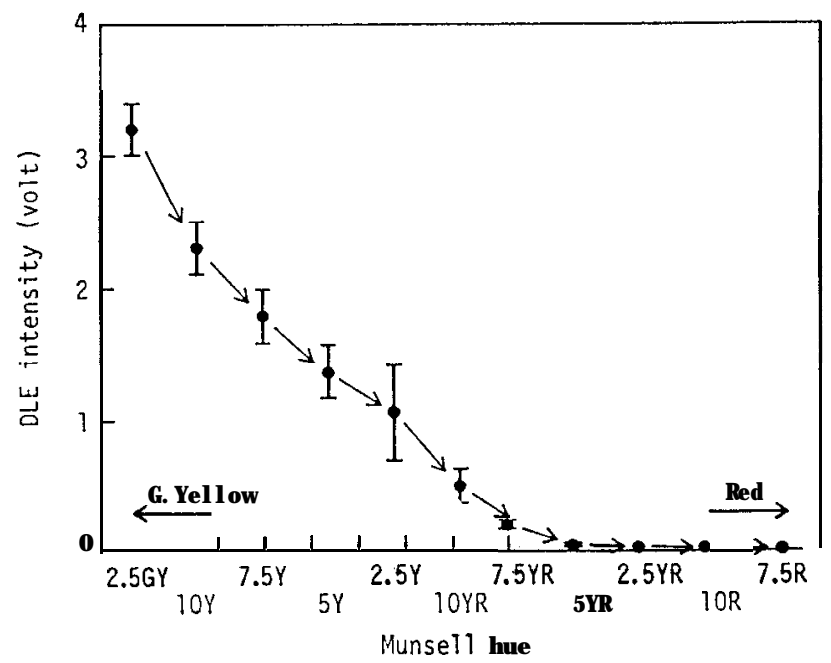

Fig. 3. Relationship between hue of peel color and DLE intensity of persimmon. Conditions for determination of DLE were the same as-in Fig. 1. Vertical lines: 95 percent confidence interval.

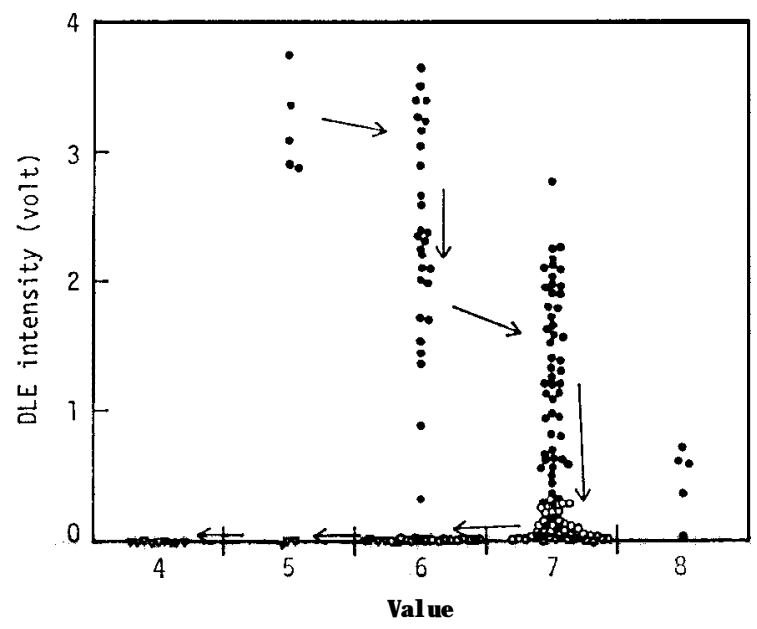

Fig. 4. Relationship between value of peel color and DLE intensity of persimmon. Conditions for determination of DLE were the same as in Fig. 1. and $\bigcirc$ were measured on the harvested day of $9 / 14$ to $10 / 19$ and $10 / 26$ to $11 / 16$, respectively; $\nabla$ : over ripe.

The relationship between chroma and DLE is shown in Fig. 5. It is known that brightness increases with an increase in the magnitude of chroma. Ripe fruit had chroma values of 12 to 14. Again, in Fig. 5, the arrows show the direction of the change of chroma with increasing time. From the above observations only hue can be estimated from DLE intensity. 


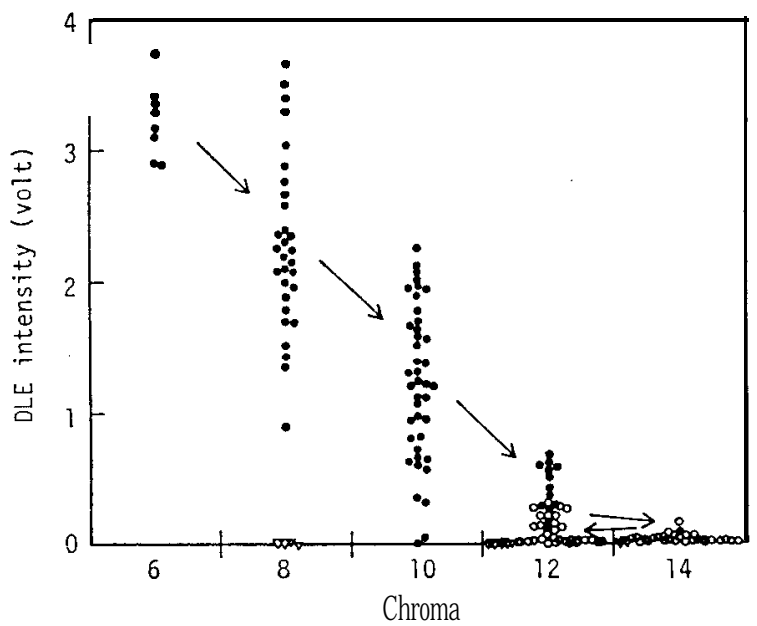

Fig. 5. Relationship between chroma of peel color and DLE intensity of persimmon. For details see legend of Fig. 4.

\section{Effect of impact bruising on DLE intensity}

Bruising (see Fig. 6) of normal fruit (N) caused a sudden increase in DLE intensity (B) with a subsequent drop in DLE after 24 hours of storage (A). These effects can cause problems in an automatic sorting machine since the increase in DLE caused by bruising could be interpreted as an unripened fruit and the depressed DLE after storage for 24 hours might be interpreted as well ripened fruit. Therefore, when DLE is used for maturity/quality sorting of persimmons the fruit should be handled very carefully to avoid bruising and sorting should take place as soon as possible after harvesting.

\section{Sorting accuracy of fruits by DLE intensity}

Peel color is one of the most important factors for standardizing persimmons as a commodity. Peel color has also been found to be related to market evaluations and acceptance by consumers. But standardization of peel color is hindered by the fact that color/quality relationships can change from one production area to another (Akimoto and Kuroda, 1979). Thus, automatic sorters in different locations may necessarily have to be standardized differently (Akimoto and Kuroda, 1980). Furthermore, in sorting plants the standards for peel color sorting may have to shift during the shipping season.

Table 1 compares the degree of coloring (50\% to $100 \%$ ) to the Munsell color chart reading of fruits from the Yoshii Sorting Plant, Fukuoka Prefecture. The table implies that it is easy to evaluate small peel color differences by the human eye, but a numerical expression of color according to the color chart is very difficult.

Munsell hue showed a high correlation with DLE intensity as shown in Fig. 3. Persimmons were classified into four color groups as shown in Table 2. "Kakugai", "Ryo", "Yu" and "Shu" correspond to poor, average, good and 

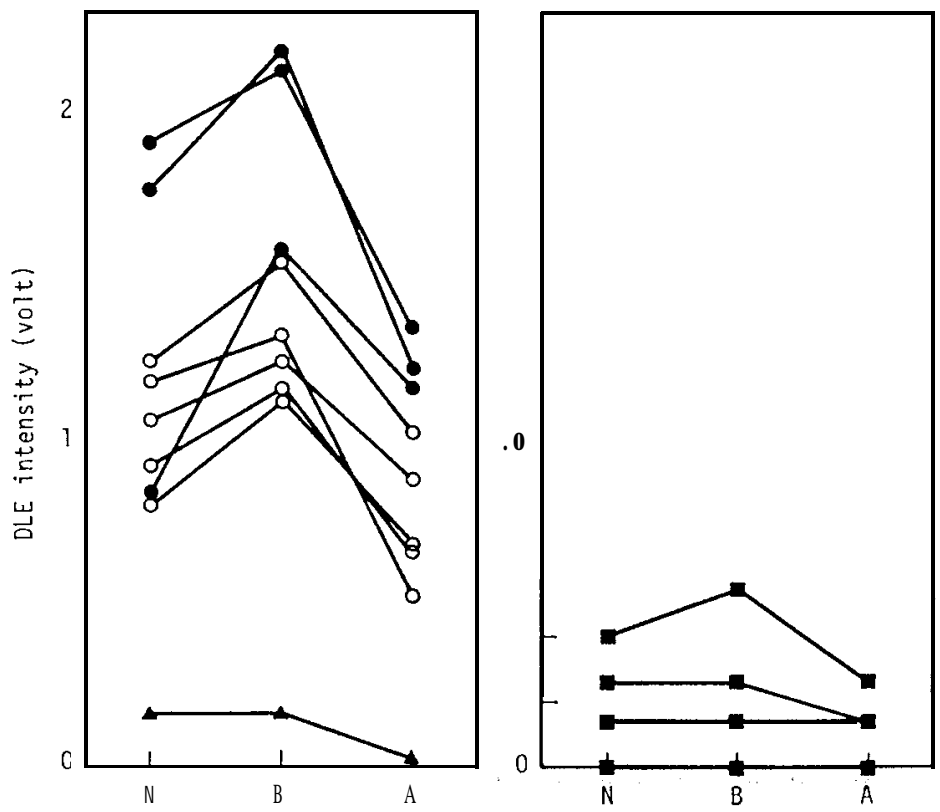

Fig. 6. Effect of bruising on DLE intensity of persimmon. Conditions for determination of DLE: $10 \mathrm{~min}$ dark period, $2 \mathrm{sec}$ excitation period, 1,750 Ix illuminance, and $0.7 \mathrm{sec}$ decay period. $\mathrm{N}$ : normal; $\mathrm{B}: 10 \mathrm{~min}$ after bruising; A : $24 \mathrm{hr}$ after bruising. $\bigcirc \mathrm{O}, \mathrm{A}$, and $\mathbf{\square}$ greenish yellow, yellow, yellowish red, and red samples, respectively.

Table 1. Peel color of standard fruits in a packing house line of persimmon*.

\begin{tabular}{|c|c|c|}
\hline $\begin{array}{c}\text { Degree of coloring } \\
\text { percent }\end{array}$ & Hue, value & /chroma \\
\hline $\begin{array}{r}50 \\
60 \\
70 \\
80 \\
90 \\
100\end{array}$ & $\begin{array}{l}7.5 \mathrm{YR} \\
5 \mathrm{YR} \\
2.5 \mathrm{YR} \\
2.5 \mathrm{YR} \\
2.5 \mathrm{YR} \\
\mathbf{1 0} \mathrm{R}\end{array}$ & $\begin{array}{l}7 / 12 \\
7 / 14 \\
6 / 12 \\
6 / 12 \\
6 / 12 \\
6 / 14\end{array}$ \\
\hline
\end{tabular}

* Peel color was measured in the packing house line of the Chikugo-Yoshii Agricultural Co-operative (Fukuoka) on November 19 in $197 \mathrm{G}$.

excellent quality respectively. Table 2 gives the sorting accuracy of the four color groups of persimmons by DLE intensity. Sorting accuracies were 94.4, $84.8,62.1$, and $80.8 \%$ for groups 1 through 4 respectively. Accuracy was considered high except for group 3. Changing of fruit color from group 3 to group 4 was as high as $34.5 \%$, but the change beyond adjacent groups did not occur. Fruit temperature, ranging from 17.0 to $22.0^{\circ} \mathrm{C}$, was not optimum for the measurement of DLE. Nonetheless, good results were obtained during 
Table 2. Sorting accuracy of color groups of persimmons by means of DLE intensity.

\begin{tabular}{|c|c|c|c|c|c|c|}
\hline \multirow{3}{*}{$\begin{array}{l}\text { Color } \\
\text { group }\end{array}$} & \multirow{3}{*}{ Class } & \multirow[b]{2}{*}{$\begin{array}{l}\text { Peel color } \\
\text { Munsell hue } \mathrm{N} \mathrm{b} \mathrm{b} \mathrm{r}\end{array}$} & \multicolumn{4}{|c|}{$\begin{array}{l}\text { Sorting accuracy of color group by } \\
\text { means of DLE intensity*, percent }\end{array}$} \\
\hline & & & $\begin{array}{l}\text { Color group by } \\
\text { DLE intensity }\end{array}$ & 1 & 3 & 4 \\
\hline & & & $\begin{array}{l}\text { Range of detector } \\
\text { response, volt }\end{array}$ & $\begin{array}{cl}0.65 & 0.65 \\
\text { and over } & -0.10\end{array}$ & $\begin{array}{l}0.10 \\
-0.02\end{array}$ & $\begin{array}{c}\text { below } \\
0.02\end{array}$ \\
\hline $\begin{array}{l}1 \\
2 \\
3 \\
4\end{array}$ & $\begin{array}{l}\text { "Kokügai" } \\
\text { "Yu" } \\
\text { "Shu" }\end{array}$ & $\begin{array}{cc}* 7.5 \mathrm{Y}, 5 \mathrm{R}, 5 \mathrm{Y} 10 \mathrm{Y} 7.5 \mathrm{YR} & 3633 \\
5 \mathrm{YR} & 29 \\
2.5 \mathrm{Y} \mathrm{R}, 10 \mathrm{R} & 26\end{array}$ & & $\begin{array}{r}5.6 \\
84.8 \\
3.4\end{array}$ & $\begin{array}{r}6.1 \\
62.1 \\
19.2\end{array}$ & $\begin{array}{l}34.5 \\
80.8\end{array}$ \\
\hline
\end{tabular}

sorting of persimmons under $1,750 \mathrm{~lx}$.

\section{SUMMARY AND CONCLUSIONS}

DLE of persimmons (Fuyu fruits) were measured in order to demonstrate the potential of DLE for measuring maturity and peel color. Measurements were made under the standard conditions of 1,750 lx excitation for $2 \mathrm{sec}$ after a secondary dark period of $10 \mathrm{~min}$. The results support the following conclusions.

1. DLE intensity of persimmons decreased with time and the concomitant decrease in chlorophyll content of the fruits.

2. Munsell hue can be estimated from DLE measurements. Because of its sensitivity DLE may be a better measure of maturity than Munsell hue.

3. Bruising of the fruit causes a short-term increase in DLE, but after 24 hours of storage the DLE was found to be lower than that of the unbruised fruit.

4. DLE measurements of Munsell hue were found to have accuracies from $62.1 \%$ to $94.4 \%$ with the " $Y u$ " class giving the lowest accuracy. The "Kakugai" class was the easiest class to measure with DLE. Thus, DLE was considered to be a practical method for objectively sorting persimmons.

\section{ACKNOWLEDGEMENT}

This work was supported by a Grant-in-Aid for Co-operative Research (A 036027), the Ministry of Education, Science and Culture, 1975.

\section{REFERENCES}

Akimoto, K. and S. Kuroda 1979 Influence of peel color of Kaki (Diospyros Kuki L. cv.

Fuyu) on the knockdown price. J. Soc. Agr. Machinary, Japan, 41: 309-312

Akimoto, K. and S. Kuroda 1980 On grading work of Kaki (Diospyros Kuki L. cv. Fuyu). (3) 
Properties of producers, distributors and consumers on criterion of judgments for grading. J.Soc. Agr. Machinary, Japan, 42: 435-441

Chuma, Y., K. Nakaji and W. F. McClure 1982 Delayed light emission as a means of automatic color sorting of persimmon fruits (Part 1). DLE fundamental characteristics of persimmon fruits. J. Fac. Agr., Kyushu Univ., 27: 1-12 